\title{
Establishment of fluoroscopy views and standardized procedure of percutaneous magic screw insertion for acetabulum fractures
}

\author{
Jiantao Li, Zhirui Li, Xiang Wang, Gongzi Zhang, Ye Peng, Shuwei Zhang, Peifu Tang ${ }^{*}$ and Lihai Zhang* (D)
}

\begin{abstract}
Background: To place the magic screw more simply, we established a set of reproducible fluoroscopic views and a standardized procedure of magic screw insertion.

Materials and methods: This study on the magic screw tunnel uses a three-dimensional reconstruction model and a skeleton projection. The 3D model of the pelvis was made to be transparent and it was rotated to the place where the ischial spine was just sheltered by the posterior wall of the acetabulum. The angles of this view projection were recorded in the transverse plane and coronal plane. Six cadaveric pelvises (three males, three female) were used to validate the proper projection angle of the C-arm fluoroscopy. The skeleton specimens were all positioned latericumbent on a radiolucent table.

Result: In all pelvis 3D models, all magic cylinders with a $7.3 \mathrm{~mm}$ diameter were successfully inserted along the bone structure tunnel in 30 3D pelvic models. The average angle of the transverse view rotated by the C-arm fluoroscopy was $162^{\circ}$ in males and $157^{\circ}$ in females, the angle of the coronal plane was $22^{\circ}$ in males and $24^{\circ}$ in females. The average distance between the front wheel of the $\mathrm{C}$-arm machine and the middle axial line of the radiolucent bed was $43 \mathrm{~cm}$ in males and $43 \mathrm{~cm}$ in females. In skeleton pelvis research, all the screws were safely inserted using this method.

Conclusion: The magic screw technique could be a good choice for the treatment of acetabular fractures, especially quadrilateral plate fractures. If the proper fluoroscopy view technique is used properly, the magic screw can be inserted rapidly and safely.
\end{abstract}

Keywords: Percutaneous magic screw, Acetabular fractures, 3D reconstruction model, Fluoroscopy views

\section{Background}

Acetabular fractures are characteristic injuries in high energy trauma patients, which remains to be the most challenging fracture for surgeons due to the complex anatomy and complicated injury mechanism [1]. The most used classification of acetabular fractures is the Letournel and Judet, which could properly guide the selection of treatment strategies [2].

Medial wall fractures of the acetabulum (quadrilateral plate) [3] are frequently encountered in fractures such as

* Correspondence: pftang301@126.com; zhanglihai74@qq.com Orthopedic Department, Chinese PLA General Hospital, Fuxing Road, 28, Beijing 100853, People's Republic of China that of both column, anterior column and posterior hemitransverse, transverse, posterior column, or T-type fractures [4-7]. The fixation of the quadrilateral plate has been complicated and includes a risk of hip joint penetration [8, 9]. One percutaneous screw fixation technique, reported to hold the quadrilateral plate in a reduced position, was described as the "Magic screw" [10]. The effect of the magic screw to fix the quadrilateral plate can be the same as that of the posterior column screw, but is more convenient for body positioning, less invasive to the soft tissue, and has a higher strength to hold the quadrilateral area. However, the placement of the magic screw is technically demanding, even for an

(c) The Author(s). 2018 Open Access This article is distributed under the terms of the Creative Commons Attribution 4.0 International License (http://creativecommons.org/licenses/by/4.0/), which permits unrestricted use, distribution, and reproduction in any medium, provided you give appropriate credit to the original author(s) and the source, provide a link to the Creative Commons license, and indicate if changes were made. The Creative Commons Public Domain Dedication waiver (http://creativecommons.org/publicdomain/zero/1.0/) applies to the data made available in this article, unless otherwise stated. 
experienced orthopedic surgeon in our clinical practice $[10,11]$. The optimal starting points, direction, and depth of a safe zone in the posterior column of the acetabulum and the accuracy of inserting these screws have always been controversial.

To place the magic screw more simply, a set of reproducible fluoroscopic views and a standardized procedure of magic screw insertion were established. This study delineates the technique of screw penetration based on anatomic studies, the readily reproducible fluoroscopic view, and the clinical practice in order to establish this new method.

\section{Materials and methods}

All investigations were carried out in accordance with the ethical guidelines and were approved by the Institutional Ethical Review Committee of Chinese PLA General Hospital. All patients agree to use their data.

\section{The study on the magic screw tunnel using the three- dimensional reconstruction model}

We collected the Digital Imaging and Communications in Medicine format (DICOM) of 30 patients and imported these into a personal computer. The DICOM data was extracted from 30 patients ( 15 male, 15 female, ages $26 \sim 82$, height $155 \sim 183 \mathrm{~cm}$, weight $48 \sim 80 \mathrm{~kg}$ ) without deformity, fracture, or tumors who underwent computed tomography angiography in our hospital (Siemens Sensation Open 128-slice CT scanner; Siemens,
Erlangen, Germany). Power settings were typically $100 \mathrm{kV}, 105 \mathrm{~mA}$, and $750 \mathrm{~ms}$ rotation time with a slice thickness of $1.2 \mathrm{~mm}$. The field of view was $512 \times 512$ pixels with increments of $1.2 \mathrm{~mm}$, using detector collimation of $128 \times 0.625 \mathrm{~mm}$ (pitch 0.933 ). Then, the consecutive CT data were imported to the image-processing software of Mimics 15.0 (Materialise, Leuven, Belgium). All three-dimensional pelvis models were constructed through protocols including those for thresholding, region growing, masks editing, polylines calculation, and cavity filling from polylines.

After the pelvis reconstruction, a cylinder with a $7.3 \mathrm{~mm}$ diameter was created with an average length of $73 \mathrm{~mm}$ (range 67-93 $\mathrm{mm}$ ) using the function module of MedCAD in Mimics. One end side of the cylinder was placed on the lower part of the gluteus medius pillar, and the other end side was just medial to the ischial spine. The location of the cylinder was slightly adjusted to make it walk in the bone tunnel behind the acetabulum (Fig. 1). The 3D model of the pelvis was made to be transparent and it was rotated to the place where the ischial spine was just sheltered by the posterior wall of the acetabulum. The bone tunnel is shown in Fig. 2. The angles of this view projection were recorded in the transverse plane and coronal plane.

\section{The study on the skeleton projection}

Six cadaveric pelvises (three male, three female) were used to validate the proper projection angle of the
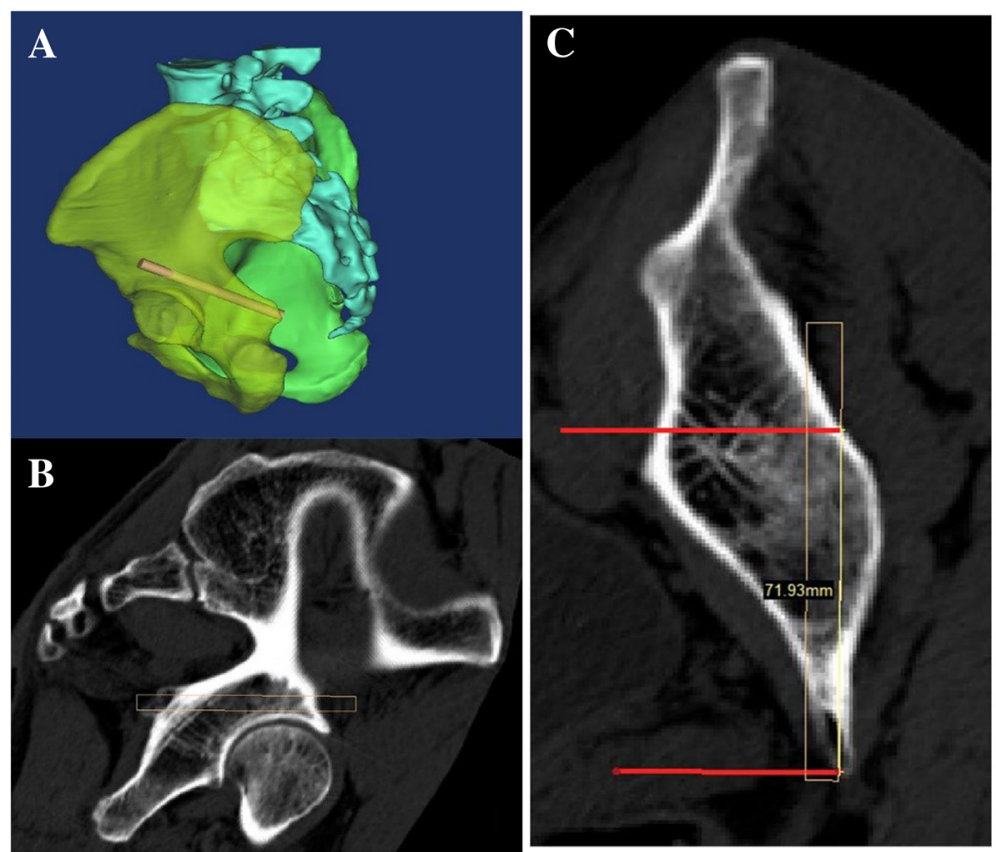

Fig. 1 a The cylinder was walking along the bone channel behind the acetabular. b, c Through slightly adjusting the location of the cylinder, we confirmed that it was in the proper position without penetration into the hip joint 

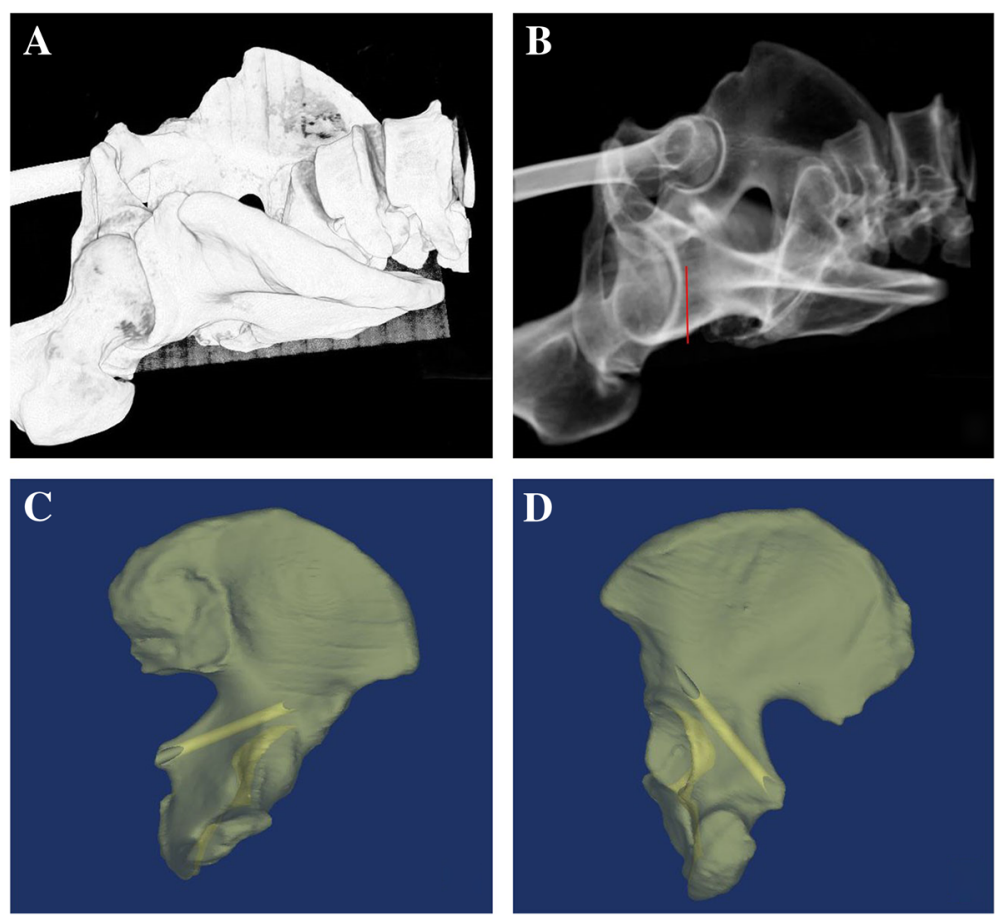

Fig. $\mathbf{2}$ a, b The 3D model of the pelvis is shown and rotated to the right place where the ischial spine was just sheltered by the posterior wall of the acetabulum. The magic screw is manually depicted with the red line shown on picture B. $\mathbf{c}$, $\mathbf{d}$ The magic screw channel is shown on the model

C-arm fluoroscopy,which was performed in Beijing Aerospace General Hospital Discipline of Anatomy. The skeleton specimens were all positioned latericumbent on a radiolucent table. First, the standard lateral view of the pelvis was obtained, then the $\mathrm{C}$-arm was rotated to the angles of the coronal and transverse plane. The images were recorded in every 5 degrees of rotation. When the proper image showed ischial spine overlapping with the posterior wall of the acetabulum, the position and rotation degree of $\mathrm{C}$-arm fluoroscopy were recorded. $\mathrm{Di}$ rected by fluoroscopic image, the starting point for the guide wire was $2 \mathrm{~cm}$ above the roof of the acetabulum on the gluteus medius pillar. The direction of the guide wire was to the ischial spine. With the starting point and the direction mentioned above, the guide wire was inserted and the magic screw was finally placed successfully (Fig. 3).

\section{Clinical application}

Finally, a minimally displaced quadrilateral plate fracture was fixed with a percutaneous screw using this method. The patient was a 38 year old male, and the mechanism of the injury was a traffic accident. The fracture was on the left side. The time from injury to surgery was 4 days. According to OTA classification, the fracture model was 61-A2.3. The surgeon was a senior doctor with more than 10 years of experience in pelvis/acetabular cases.
This case was performed using AP, inlet, and outlet plain radiographs after surgery.

The patient was placed on a radiolucent bed in the latericumbent position before general anesthesia, with the fracture side close to the edge of the bed. The axial view was verified by fluoroscopy and the magic screw technique was used. After the patient's skin was circumferentially prepared and draped, the starting point of the body surface projection was found under the guidance of the lateral pelvis image. A $3 \mathrm{~cm}$ incision was made on the surface of the anterior column screw, which is on the gluteus medius pillar. After the entry-point was found, through rotating the fluoroscopy to the right place, the proper image was found as mentioned above. The $3.5 \mathrm{~mm}$ guide wire was placed into the bone percutaneously hand directed by the image. A mallet was used to gently insert the guide wire into the bone cortex (about $2 \mathrm{~mm}$ ). A drill was not used because we feel that the mallet technique allows for better control. Under the C-arm fluoroscopic image, we could observe the guide wire crossing the fracture site, located at the exit-point of the ischial spine. After the placement of the wire and measurement of the depth, the screw was inserted with a $7.3 \mathrm{~mm}$ diameter and $75 \mathrm{~mm}$ length over the guide wire to fix the fracture. Final films included the iliac oblique, A-P, and obturator oblique views to ensure the screw was positioned at the right place without penetration in the hip joint. 

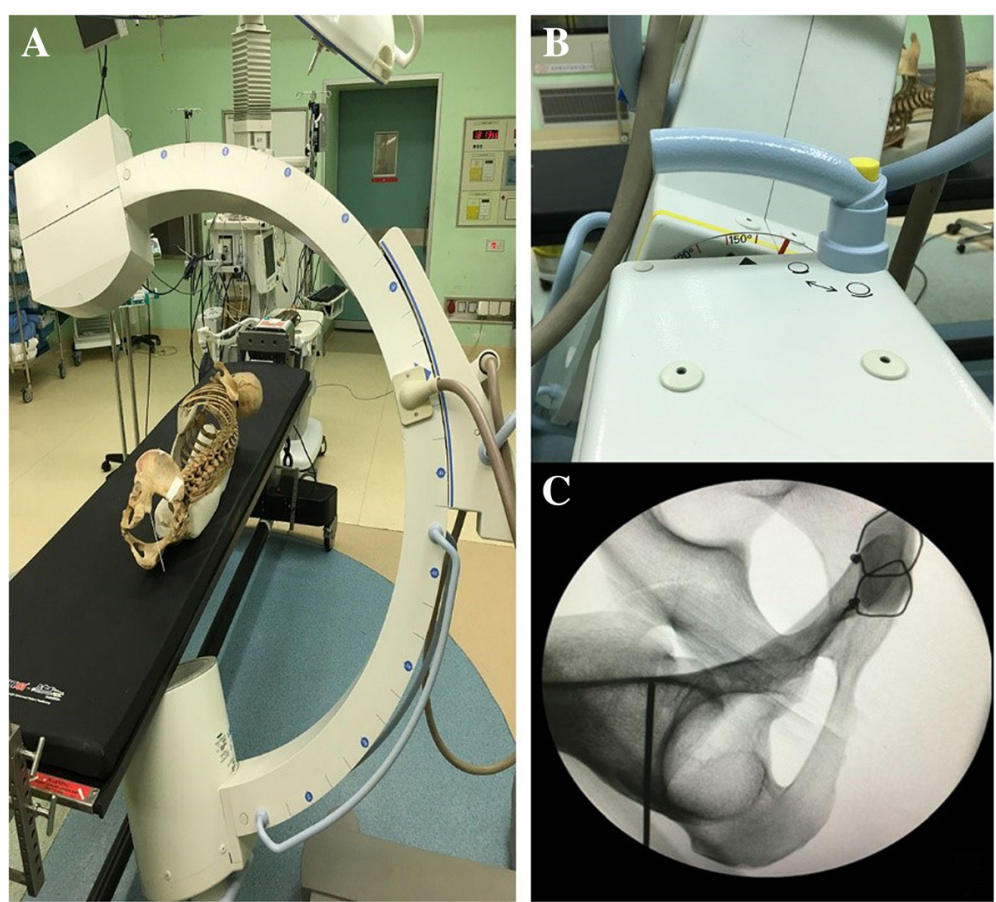

Fig. $\mathbf{3}$ a, $\mathbf{b}$ The C-arm fluoroscopy was rotated to the proper angle. $\mathbf{c}$ We inserted the nail from the lower part of the gluteus medius pillar to the ischial spine under fluoroscopic image monitoring

\section{Results}

In all pelvis 3D models, all magic cylinders with a $7.3 \mathrm{~mm}$ diameter were successfully inserted along the bone structure tunnel in 30 three-dimensional pelvic models. In skeleton pelvis research, all the screws were safely inserted using this method. The position and the rotation angle of the $\mathrm{C}$-arm fluoroscopy were recorded in the skeleton specimen projection procedure. The average angle of the transverse view rotated by the $\mathrm{C}$-arm fluoroscopy was $162^{\circ}$ in males and $157^{\circ}$ in females, the angle of the coronal plane was $22^{\circ}$ in males and $24^{\circ}$ in females. The average distance between the front wheel of the $\mathrm{C}$-arm machine and the middle axial line of the radiolucent bed was $43 \mathrm{~cm}$ in males and $43 \mathrm{~cm}$ in females (Table 1).

In clinical practice, the quadrilateral plate fractures of the patient were fixed by this method. The standard procedure based on this technique is shown in Fig. 4. The standard lateral image of magic screw projection can be achieved reproducibly during the surgery. Under this technique, the screw was inserted in a good position without penetration into the hip joint or vessel injury. The fluoroscopy time was $48 \mathrm{~s}$, and the time of the magic screw fixation surgery was $40 \mathrm{~min}$.

The patient was kept non-weight bearing for 8 weeks and advanced to weight bearing as tolerated at 2 months. This patient was followed-up at one year, and was healed. We did not observe any complications like venous thrombosis, screw breakage, reduction loss, dyspareunia, etc.

\section{Discussion}

The magic screw is named as such because of its difficulty to shoot, and it is said that one needs supernatural powers to pass it [11]. The magic screw is used to hold the reduced quadrilateral plate as part of an initially

Table 1 Angles for Males and Females in Axial View

\begin{tabular}{lllll}
\hline Sex & Numbers & Transverse Plane, degrees & Coronal Plane, degrees & Distance $(\mathrm{cm})$ \\
\hline Male & 1 & $157^{\circ}$ & $20^{\circ}$ & 45 \\
& 2 & $165^{\circ}$ & $25^{\circ}$ & 40 \\
& 3 & $165^{\circ}$ & $20^{\circ}$ & 43 \\
Female & 1 & $150^{\circ}$ & $25^{\circ}$ & 40 \\
& 2 & $157^{\circ}$ & $23^{\circ}$ & 45 \\
& 3 & $165^{\circ}$ & $25^{\circ}$ & 45 \\
\hline
\end{tabular}




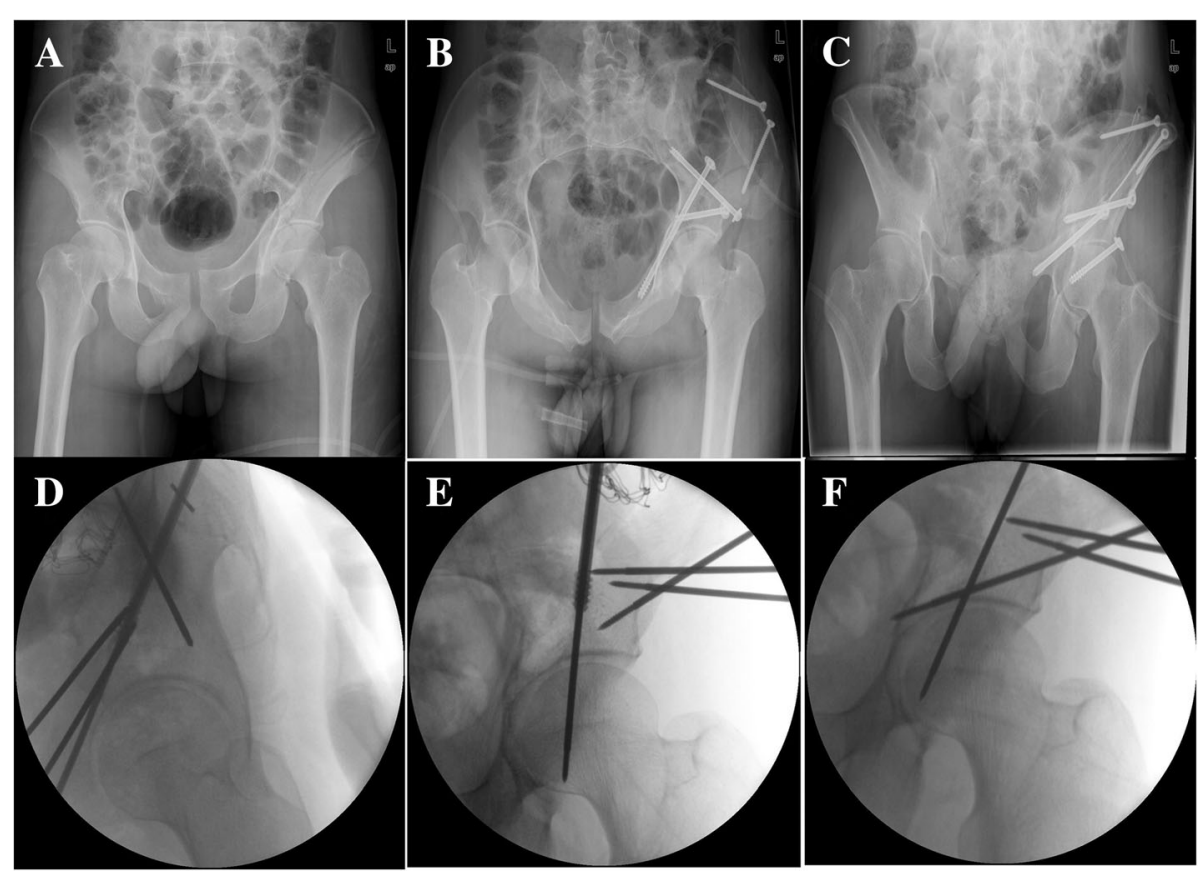

Fig. 4 The standard procedure based on this technique. a Preoperative anteroposterior view of pelvic; b Postoperative inlet pelvic view; c Postoperative outlet pelvic view; $\mathbf{d}$ Intraoperative lateral views for placing K-ware; e and $\mathbf{f}$ intraoperative iliac oblique radiography view for placing K-ware

displaced acetabular fracture. As it crosses the posterior column, it can also be used as an alternative to stabilize the quadrilateral fractures involving the posterior column [10]. The entry-point of the magic screw is similar to that of an anterior column screw, which is on the gluteus medius pillar, but near the roof of the acetabulum. The tunnel of this is behind the hip joint, directly down towards the posterior column and medially towards the ischial spine [12].

However, to our best knowledge, this is the first time that the methods and techniques of the magic screw from radiological and operative aspects have been described. Using the Mimics software, we found the location of the magic screw channel in 30 pelvic models, and of which the space within the bone structures channel was large enough to inset a $7.3 \mathrm{~mm}$ lag screw. We reconstructed every 3D pelvic model and used rotated angles to guide and manipulate the rotation of the $\mathrm{C}$-arm fluoroscopy to a get proper projection image. The $1.2 \mathrm{~mm}$ thickness of DICOM data used in the research makes the 3-D pelvic models clear. Besides the digital research process, the skeleton study was adopted to verify the feasibility of the magic screw technique, through which we recorded the accurate angle and distance to locate the $\mathrm{C}$-arm fluoroscopy in the right place. Both procedures mentioned previously were the foundation to guarantee the feasibility and security of the magic screw to be used in clinical practice.
The technique of percutaneous screw fixation used to fix the acetabular fracture was first described by Routt and Starr in the 1990s [13, 14]. In 2001, professor Starr introduced different kinds of techniques about the percutaneous screw fixation and firstly proposed the magic screw to fix the quadrilateral plate fractures [10]. However, he did not report any clinical trials about this technique. It was stated that on the iliac oblique view, the magic screw can be seen behind the hip joint, and it is above the joint on the AP view. Its path running in the bone structure channel can be followed on an obturator oblique view, and using a particular view, swinging between the obturator outlet and inlet views, it can be seen protruding [12]. However, it is difficult to insert the magic screw following the methods mentioned above because the message is not perceptible enough for the surgeons guided by the C-arm fluoroscopy to implant the screw.

Fluoroscopic views are always the foundation of the percutaneous screw techniques to treat the acetabular fractures. Due to the complicated morphology of the pelvic structure and the differing position of the patient, the appropriate fluoroscopic image is frequently unachievable during the surgery [15-17]. Operation time will be extended while finding the ideal image and the entry point [18], especially when the standard fluoroscopic view was not established. Recording the position and the rotation angle of the C-arm fluoroscopy 
preoperatively can facilitate the percutaneous techniques and reduce radiation time $[13,14]$. In clinical practice, we use adhesive bandage as the mark sticking on the ground. The distance between the bandage and the middle axial line of the radiolucent bed was about $40 \mathrm{~cm}$. The label indicates the location of front wheel of the $\mathrm{C}$-arm. We rotate the $\mathrm{C}$-arm to the angle of $160^{\circ}$ and $20^{\circ}$, and sometimes move the $\mathrm{C}$-arm forwards or backwards. By taking the pictures of the pelvis, we slightly adjust the angel of C-arm. It's practical to get the proper picture by finding the proper angle without too much difficulty.

Through 3D model and skeleton research, we confirmed the proper angle of the projection view in the transverse and coronal planes, by which we insert the magic screw into the specimen successfully. A gender factor was found that affected the rotation angle of $\mathrm{C}$-arm fluoroscopy. The mean distance between the front wheel of the $\mathrm{C}$-arm machine and the middle axial line of the radiolucent bed was $43 \mathrm{~cm}$. The distance did not change much in different samples. Guided by the angles and distance measured above, it was easy to find the proper radiologic image and facilitated the insertion of the magic screw, which passed through the bone channel safely and directly. In the clinical practice, we successfully inserted the magic screw with less radiation. Additionally, the 40-min fixation time was satisfied. The fracture healed without any complications.

In our experience, some important aspects should be mentioned: (1) The reslice project function in Mimics software was useful to rebuild the orthogonal planes depended on the inserted cylinder, through which we could check whether the $7.3 \mathrm{~mm}$ screw was properly in the safe zone without penetration. (2) It is better to place the patient close to the edge of the affected side on the operating bed since it allows for more convenient manipulation of the C-arm fluoroscopy. (3) A mallet was used instead of a drill to advance the guide wire within the bone channel because it is easier for us to control the mallet technique without violating the outer corridor of the channel. (4) It is better to keep the end of the screw located on the ischial spine, because shooting laterally endangers the sciatic nerve and medially affects the pelvic viscera.

\section{Conclusion}

The magic screw technique could be a good choice for the treatment of acetabular fractures, especially quadrilateral plate fractures. If the proper fluoroscopy view technique is used properly, the magic screw can be inserted rapidly and safely. However, our study has some limitations. All the CT data of the patients are from Chinese records, which may limit extrapolation of the results to other nationalities. The number of cases in our study is relatively small. Finally, there is no control group with which to compare the clinical results. More prospective randomized controlled trials are needed to overcome the limitations of our research.

\section{Abbreviations \\ 3D: Three dimensional; CT: Computed tomography; DICOM: Digital Imaging and Communications in Medicine format}

\section{Funding}

This study was supported by The National Natural Science Foundation of China (31370947, 61771489), for payment data operations and measurements.

\section{Availability of data and materials}

The data supporting your findings can be found, and have be presented within the manuscript

\section{Authors' contributions}

$L J$ and LZ data collection and writing the article; ZG and WX data collection; PY and ZS analysis and interpretation; ZL and TP conception and design, critical revision of the article and obtaining funding. All authors read and approved the final manuscript.

\section{Ethics approval and consent to participate}

This study involved medical imaging investigation and was approved by the ethics committee of the Chinese PLA General Hospital. All patients agree to use their data.

Six cadaveric pelvises were performed in Beijing Aerospace General Hospital Discipline of Anatomy which come from donations.

\section{Consent for publication}

Informed consent was obtained from all individual participants included in the study.

\section{Competing interests}

The authors declare that they have no competing interests.

\section{Publisher's Note}

Springer Nature remains neutral with regard to jurisdictional claims in published maps and institutional affiliations.

Received: 5 May 2018 Accepted: 13 August 2018

Published online: 12 September 2018

\section{References}

1. Hirvensalo E, Lindahl J, Kiljunen V. Modified and new approaches for pelvic and acetabular surgery. Injury. 2007;38(4):431-41. https://doi.org/10.1016/j. injury.2007.01.020.

2. Judet R, Judet J, Letournel E. Fractures of the acetabulum: classification and surgical approaches for open reduction. Preliminary Report J Bone Joint Surg Am. 1964;46:1615-46

3. Laflamme GY, Delisle J, Leduc S, Uzel PA. Isolated quadrilateral plate fracture: an unusual acetabular fracture. Canadian journal of surgery journal canadien de. chirurgie. 2009;52(5):E217-9.

4. White G, Kanakaris NK, Faour O, Valverde JA, Martin MA, Giannoudis PV. Quadrilateral plate fractures of the acetabulum: an update. Injury. 2013;44(2): 159-67. https://doi.org/10.1016/j.injury.2012.10.010.

5. Tosounidis TH, Gudipati S, Panteli M, Kanakaris NK, Giannoudis PV. The use of buttress plates in the management of acetabular fractures with quadrilateral plate involvement: is it still a valid option? Int Orthop. 2015; 39(11):2219-26. https://doi.org/10.1007/s00264-015-2883-7.

6. Prasartritha $T$, Chaivanichsiri $P$. The study of broken quadrilateral surface in fractures of the acetabulum. Int Orthop. 2013;37(6):1127-34. https://doi.org/ 10.1007/s00264-013-1845-1.

7. Barnes SN, Stewart MJ. Central fractures of the acetabulum: a critical analysis and review of literature. Clin Orthop Relat Res. 1976;114:276-81.

8. Laflamme GY, Hebert-Davies J, Rouleau D, Benoit B, Leduc S. Internal fixation of osteopenic acetabular fractures involving the quadrilateral plate. Injury. 2011;42(10):1130-4. https://doi.org/10.1016/j.injury.2010.11.060. 
9. Park MS, Yoon SJ, Park JH, Choi SM. The management of the displaced medial wall in complex acetabular fractures using plates and additional cerclage. Hip international : the journal of clinical and experimental research on hip pathology and therapy. 2013;23(3):323-9. https://doi.org/10.5301/ hipint.5000027.

10. Starr A, Borer D, Reinert C. Technical aspects of limited open reduction and percutaneous screw fixation of fractures of the acetabulum. Operative Techniques Orthop. 2001;11(3):218-26.

11. Ruan Z, Luo CF, Zeng BF, Zhang CQ. Percutaneous screw fixation for the acetabular fracture with quadrilateral plate involved by three-dimensional fluoroscopy navigation: surgical technique. Injury. 2012;43(4):517-21. https:// doi.org/10.1016/j.injury.2011.08.002.

12. Perter $B, A d a m ~ S$, Charles $R$ The percutaneouse treatment of pelvic and acetabular. The percutaneouse treatment of pelvic and acetabular(2010).

13. Routt ML Jr, Simonian PT. Closed reduction and percutaneous skeletal fixation of sacral fractures. Clin Orthop Relat Res. 1996;329:121-8.

14. Routt ML Jr, Simonian PT. Internal fixation of pelvic ring disruptions. Injury. 1996;27(Suppl 2):B20-30.

15. Kendoff D, Gardner MJ, Citak M, Kfuri M Jr, Thumes B, Krettek C, Hufner T. Value of 3D fluoroscopic imaging of acetabular fractures comparison to 2D fluoroscopy and CT imaging. Arch Orthop Trauma Surg. 2008;128(6):599605. https://doi.org/10.1007/s00402-007-0411-y.

16. Borrelli J Jr, Ricci WM, Steger-May K, Totty WG, Goldfarb C. Postoperative radiographic assessment of acetabular fractures: a comparison of plain radiographs and CT scans. J Orthop Trauma. 2005;19(5):299-304.

17. Hufner T, Stubig T, Citak M, Gosling T, Krettek C, Kendoff D. Utility of intraoperative three-dimensional imaging at the hip and knee joints with and without navigation. J Bone Joint Surg Am. 2009;91(Suppl 1):33-42. https://doi.org/10.2106/jbjs.h.01441.

18. Zhang L, Zhang W, Mullis B, Liu D, Xiong Q, Lv H, Ji X, Peng Y, Tang P. Percutaneous anterior column fixation for acetabulum fractures, does it have to be difficult?-the new axial pedicle view of the anterior column for percutaneous fixation. J Orthop Trauma. 2016;30(1):e30-5. https://doi.org/10. 1097/bot.0000000000000424.

Ready to submit your research? Choose BMC and benefit from:

- fast, convenient online submission

- thorough peer review by experienced researchers in your field

- rapid publication on acceptance

- support for research data, including large and complex data types

- gold Open Access which fosters wider collaboration and increased citations

- maximum visibility for your research: over $100 \mathrm{M}$ website views per year

At $\mathrm{BMC}$, research is always in progress.

Learn more biomedcentral.com/submissions 